\title{
PEDAGOGIAS EM DESACATO: ATOS DE UMA INTELIGÊNCIA QUE NÃO OBEDECE SENÃO A ELA MESMA
}

\section{DISOBEYING PEDAGOGIES: ACTS OF AN INTELLIGENCE OBEYING ONLY ITSELF}

\author{
Raul Antelo \\ Universidade Federal de Santa Catarina, UFSC, Florianópolis, SC, Brasil
}

\begin{abstract}
Resumo: Dois fatores estão em jogo no ato de aprendizagem: inteligência e vontade. A pura relação de vontade a vontade é a relação normal entre professor e aluno. Mas, toda vez que uma inteligência subordina-se a outra, há embrutecimento. O estudante deve ser levado não só a um desejo, mas também a uma inteligência, a do livro. Rancière (2012) denomina emancipação a muito conhecida diferença dessas duas relaçôes: o ato de uma inteligência obedecendo somente a si mesma, mesmo quando uma vontade obedece a outra vontade.
\end{abstract}

Palavras-chave: Imagem; Emancipação; Pedagogia.

Abstract: There are two faculties at play in the act of learning: intelligence and will. A pure relationship of will to will is the currant dialogue between master and student. But whenever an intelligence is subordinated to another there is stultification. The student should be linked to a will and also to an intelligence, the book's. Rancière (2012) calls the very well known difference of the two relations - the act of an intelligence obeying only itself even while the will obeys another will - emancipation.

Keywords: Image; Emancipation; Pedagogy.

No cinema, repetiçāo e corte perfazem um sistema; são inseparáveis. Ambos realizam a tarefa messiânica do cinema. Essa tarefa, tal como aparece em Histoire(s) du cinéma, não é de criação mas é um ato de decriação (AGAMBEN, 1995, p. 68) ${ }^{1}$.

\footnotetext{
${ }^{1}$ Em Agamben and Theology (2011, p. 38), Colby Dickinson explica que, para o filósofo italiano, que usa, aliás, esse conceito em relação a Bartleby, "ethics can be said to unfold anew from a realization of our true vocational calling. If there were some preordained sense of who we are, or who we are all called to be, there would be little sense in having an 'ethics' at all [...]. Our freedom, then, is found within our lack of a specific vocation, what Leland de la Durantaye has referred to as a decreation of our created selves, a word which would seem to evoke the sheer radicality of what Agamben is proposing". Massimo Cacciari usa também o conceito de de-creatio, por exemplo, em relação a um profanador como Duchamp. Seu $N u$ descendo a escada marca, por sinal, o oposto que as coroaçōes ou sagraçóes, o caminho ad inferos.
} 
Para pensarmos as atuais relaçóes entre literatura e política, é preciso, antes de mais nada, observar que as práticas e os dispositivos de poder já não se aplicam sobre o cidadáo, entendido como ator político preferencial, mas, prioritariamente, sobre o ser biológico do homem, conforme Foucault (2004a; 2004b) e Esposito (2002; 2010). Isso acarreta um deslocamento do foco tradicional, jogado sobre a Estética, para reorientá-lo em direção à Aisthesis, como objeto da estética, evidentemente, mas também como efeito da organizaçáo da mídia, operação com que se reconfigura a sensibilidade contemporânea. O motivo pode ser explicado tanto pelo papel preponderante das técnicas visuais na nossa sociedade, segundo Déotte (1993; 1997; 2004; 2005; 2006; 2012; 2015), quanto por certa exemplaridade que a imagem passa a desempenhar entre nós.

Com efeito, a questão do exemplum mostra os modos divergentes com que a verdade clássica e a verdade característica do "realismo" podem, através do relato, representar o passado. Um paradigma, em poucas palavras, é um exemplo que, pelo simples fato de sua exemplaridade, se torna um modelo. Para Agamben, relembremos, o paradigma é um conceito que foge da antinomia hegeliana entre o universal e o particular, para se apresentar como uma singularidade qualquer, detentora, porém, da possibilidade de ocupar o lugar de cada uma das outras, isto é, valendo por todas elas. Para Foucault, o exemplo-paradigma articula-se com o seu ceticismo histórico em relação aos universais. Para Agamben, porém, essa tensão resolve-se através do conceito de signatura. Sob o ponto de vista ético-político, diríamos entáo que Foucault tende a uma dramática discursiva das formas de subjetivaçáo, ao passo que Agamben, no entanto, inclina-se a uma pragmática das forças, na opinião de Castro (2012, p. 53-75). Sob essa perspectiva, uma imagem bem pode então ser um exemplo se sua função for construir e tornar inteligível todo um contexto histórico altamente problemático. Passam, então, ao primeiro plano, os problemas dos limites do relato, as restriçóes da linguagem e, consequentemente, a possibilidade de um contato místico, isto é, direto, com o passado. A questáo conhece duas vertentes. Uma mostra a perplexidade dos pensadores diante de um caso extremo como o genocídio. Outra, porém, interessa-se por um contato direto com o passado, que nos permitiria sentir esse passado como uma autêntica experiência. Temos aí as leituras de Carlo Ginzburg (1976, 1989), Hayden White (1995), Martin Jay (1993), John Felstiner (1998, 2001), o livro de Berei Lang (1990), ou os trabalhos de Dominick La Capra (1983), de Susan Buck-Morss (1996), de Giorgio Agamben (1998) ${ }^{2}$ e mesmo de Georges Didi-Huberman (2009; 2012; 2013; 2016; 2017).

${ }^{2}$ Ver também CASTRO, 2012. 
É o que Walter Benjamin já explorara no famoso ensaio sobre a obra de arte de 1936, quando nos diz que, nas obras cinematográficas, a reprodutibilidade técnica do produto não é, como no caso da literatura, uma condição externa para sua difusão maciça.

\begin{abstract}
A reprodutibilidade técnica do filme tem seu fundamento imediato na técnica de sua produção. Esta não apenas permite, da forma mais imediata, a difusão em massa da obra cinematográfica, como a torna obrigatória. A difusão se torna obrigatória, porque a produção de um filme é tão cara que um consumidor, que poderia, por exemplo, pagar um quadro, não pode mais pagar um filme (BENJAMIN, 1987, p. 172).
\end{abstract}

O filme e, até certo ponto, a própria imagem são, de fato, uma construçáo coletiva e, mais em particular, Benjamin destaca que, na fotografia, o valor de culto começa a recuar, em todas as frentes, diante do valor de exposição, muito embora o primitivo valor de culto não se entregue sem antes oferecer resistência: "Sua última trincheira é o rosto humano. Não é por acaso que o retrato era o principal tema das primeiras fotografias. $\mathrm{O}$ refúgio derradeiro do valor de culto foi o culto da saudade, consagrada aos amores ausentes ou defuntos" (BENJAMIN, 1987, p. 174).

Em consequência, Benjamin argumenta que o processo de metamorfose pelo qual atravessa o modo de exposição, em funçãa das técnicas da reprodução, também é visível na política. Mais ainda, ele interpreta que a crise da democracia pode ser avaliada como uma crise nas condiçóes de exposição do político profissional. As atuais democracias expóem o político, de forma imediata, em pessoa, diante dos seus representados (BENJAMIN, 1987, p. 183). Assim, tais transformaçóes não teriam acontecido, evidentemente, sem o auxílio de procedimentos de vanguarda, tais como a montagem, que supóem, a rigor, dois movimentos antagônicos, repetição e corte. O dadaísmo, em particular, colocou de novo em circulação, segundo Benjamin, a fórmula básica da percepção onírica, que descreve, ao mesmo tempo, o lado tátil da percepção artística: tudo o que é percebido e tem caráter sensível é algo que nos atinge. Com isso, a montagem estimulou a demanda pelo cinema, cujo valor de distração é fundamentalmente de ordem tátil; em outras palavras, ele depende da mudança de lugares e ângulos, que atingem, intermitentemente, o espectador (BENJAMIN, 1987, p. 191-192). Portanto, a recepção através da distração, que se observa crescentemente em todos os domínios da arte e até mesmo constitui o sintoma de profundas transformaçóes nas estruturas perceptivas, tem no cinema o seu cenário privilegiado. E, nesse sentido, o cinema se revelaria assim, também, sob esse 
ponto de vista, o objeto atualmente mais importante daquela ciência da percepção que os gregos chamavam de estética (BENJAMIN, 1987, p. 194).

Ora, no posterior adendo sobre a aura, de 1938, Benjamin questionase sobre o autêntico papel do cinema, neutralizando, com isso, o ensaio de 1936, razão pela qual diríamos que o espaço da polis já é, de certo modo, "estetizado", no sentido de organizado e hierarquizado, donde, na verdade, deveríamos ressignificar a oposição final de Benjamin naquele ensaio "Eis a estetização da política, como a pratica o fascismo. O comunismo responde com a politização da arte" (BENJAMIN, 1987, p. 196) -, dizendo que a estetização do político deve ser interpretada pelo avesso, isto é, como uma anestetizaçáo generalizada, empenhada em fixar o sentido comum e a evidência, para assim imunizar toda prática simbólica alternativa que poderia questioná-la e mesmo abri-la ao imprevisto.

Para dizê-lo com Montani, via Esposito (2002), a anestetização da política relaciona-se com o dispositivo do olhar para induzir a sensibilidade, com objetivo imunitário, em um sequestro da diferença, do estranho ou do estrangeiro, em suma, do inesperado. Pelo contrário, denominaríamos como politicas todas aquelas práticas simbólicas de expansão, diferenciação e reconfiguraçáo, em que o olhar, junto com seus suplementos técnicos, conduz a sensibilidade à sua plenitude, isto é, a uma autêntica experiência.

Ambas as definiçôes poderiam, contudo, ganhar melhor visibilidade conceitual se as agruparmos sob o rótulo comum de bioestética. Aceitando essa redefiniçáa, caberia ainda discriminar uma bioestética negativa, em que a estetização da política reinscreve-se no dispositivo anestético do biopoder; e uma bioestética afirmativa, em que a politização da arte manifesta-se em sua vontade de emancipação com relação ao sentido comum e reconhece-se em sua possibilidade de contato com múltiplas posiçóes e, em suma, com a própria contingência mundana, a biopotência.

\section{Repetição: glória e horror}

O universal advém como singularidade, e só temos, de início, a precariedade de um suplemento, cuja única força reside em que nenhum predicado disponivel o obriga à submissão erudita

(BADIOU, 2008, p. 45).

Tomemos um caso recente, a publicação de uma fotografia de Hiroshima após a eclosão da bomba. Mauricio Macri ou, mais provavelmente, um filósofo-fantasma, leem a foto em meio a uma beligerante greve docente 
contra os recortes neoliberais na escola pública. Diz assim o soberano, em improvisado traje de semiótico:

[...] en la foto se ve que los chicos continuaron estudiando en una escuela sin paredes, sentados en pupitres rotos, cajones de carbón y mandarinas rodeados de su ciudad pulverizada. Dos meses después de la bomba, de pie, al frente de todos ellos volvió a estar el maestro. Dando clases como todos los días, como si nada hubiese cambiado, aunque los chicos no tuvieran ni libros ni cuadernos y muchos de ellos, tampoco padres (MACRI apud GONZALEZ, 2017, s/p).

Vemos, na foto, um professor, curiosamente, e não uma professora, figura quantitativamente mais provável de ser encontrada no espaço pedagógico atual. Mas o chocante não é basicamente isso. $\mathrm{Ou}$, antes, não é fundamentalmente isso, a diferença, o que perturba nessa leitura. $\mathrm{O}$ sociólogo Horácio González imediatamente observou que:

La materia de esas imágenes es el sufrimiento o el sacrificio, no el horario de clases, el presentismo o el incentivo bajo cuerda. Esos maestros japoneses, a los que la necia disposición de Macri para las alegorías los muestra como imaginarios rompehuelgas [furagreves], eran representantes de un gran acto educativo de testimonio y supervivencia. Es una imagen formativa primordial, pero no como la cree el Gobierno, un llamando a la sumisión, sino una cita trascendente de las maestras y maestros sobre el cuidado y nutrición del ser en la tragedia. Máxima manifestación de sacrificio por una comunidad violentada, que todo maestro encararía de la misma forma. [...] La imagen fotografiada consistía allí en volver a trazar el simbolismo del espacio público derruido. Nada tienen que ver las reclamaciones del gremialismo argentino, reconstructivo de la educación pública, que al contrario, vio esas imágenes como una declaración de guerra (GONZALES, $2017, \mathrm{~s} / \mathrm{p})^{3}$.

González recrimina ao inepto analista que fala como um estatístico, um inspetor municipal ou um contabilista: "meses después de la explosión atómica que arrasó el 90\% de los edificios, fábricas, calles, plazas y casas de esa ciudad y dejó más de 150.000 personas muertas, decenas de miles de ellas de manera fulminante", e, para tanto, detém-se, particularmente, na coordenada temporal. "Dos meses después".

3 GONZALEZ, Horacio. Macri entre cenizas. Página 12. Buenos Aires, 21 mar 2017. Disponível em: <http://www.cta.org.ar/macri-entre-cenizas.html>. Acesso em: 21 ago. 2017. González desenvolve a questáo Hiroshima na arte em seu livro de 2006. Ocuparam-se também da singular leitura da foto de Hiroshima o professor de história Diego di Bastiano (Carta desde Hiroshima. La izquierda Diario. Buenos Aires, 21 mar. 2017) e o antropólogo Eduardo Grüner (Clase-testigo. Página 12. Buenos Aires, 22 mar. 2017). 
¿Cómo lo sabe? ¿Por qué no escribió un día después? Su talento disciplinario se lo hubiera permitido. Lo que no entiende que detrás de esas planillas oficiales, la foto que tanto le interesó, muestra lo contrario, muestra un tenso espíritu reconstructivo universal. Aquí se pide reconstruir el salario y la enseñanza nacional al mismo tiempo. En Hiroshima podemos apreciar que era lo que llamamos una clase pública, porque también estaban destruidas las escuelas, cosa que su gran espíritu republicano no menciona. Esa clase era una callada protesta trascendental y espiritual (GONZALES, 2017, s/p).

Numa apreensão atordoada da potência das imagens, o improvisado leitor de fotografias desmancha e dissolve:

[...] en su conciencia indiferente el significado del nombre testimonial de Hiroshima en la historia de la humanidad. ¡Y todo para pagar unos puntos menos en una paritaria! Hace más de seis décadas, dejar caer en la claridad de un día tranquilo y algo lluvioso, un poderoso explosivo atómico sobre esa ciudad, surgió de una decisión de estados mayores clandestinos. Convertía a Hiroshima y luego a Nagasaki en experimentos alucinados, tramados en laboratorios secretos donde se cruzaba la voz del infierno con una discusión sobre el remordimiento y la carencia de conocimientos éticos sobre los usos de la ciencia en una guerra. Hiroshima es una cuestión testimonial que inicia la pregunta fundamental sobre qué horizonte de lo humano permite seguir pensando las luchas sociales y políticas ante poderes que han extendido la llamada "razón de Estado" a fronteras ya inconcebibles. A la vez, la historia de la bomba atómica es la de la historia del pensamiento científico del siglo XX y sus recovecos éticos aún irresueltos. El uranio interrogado por neutrones precisaba, en el caso de Hiroshima, complejos estudios meteorológicos, altímetros muy precisos para regular la distancia del avión con el estallido, escuadrillas de acompañamiento, nuevas significaciones para los aviones y las informaciones dadas a la tripulación, que procederían a este acto secreto que de súbito se convertiría en un disciplinamiento trágico para toda la humanidad. El comandante del avión [Paul Tibbets] que le puso en el fuselaje el nombre de su madre se jactó toda su vida de haber cumplido con su deber. En sus momentos más imaginativos, regalaba a sus amigos una maqueta de la bomba atómica con su firma incorporada (GONZALES, $2017, \mathrm{~s} / \mathrm{p})^{4}$.

O tema da aula só podia ser a destruição e o horror, o Real: o impossível de suportar na vida possível: "Podría hablarse de otra cosa, pero la silenciosa meditación del docente y los niños no podría ser otra, pues todo estaba ocurriendo frente a esos acusadores esqueletos edilicios" (GONZALES, 2017, s/p). Mas o analista bisonho, ao náo poder ver o horror, mostra carregá-lo consigo, reproduzi-lo e disseminá-lo ele mesmo, aqui e agora,

${ }^{4}$ Logo depois da II guerra, o filósofo heideggeriano Carlos Astrada analisava agudamente as relaçôes entre arte e técnica em Sociología de la guerra y filosofía de la paz (Serie Ensayos, n. 1, Buenos Aires, Universidad de Buenos Aires. Facultad de Filosofía y Letras, 1948). 
quando se revela incapaz de significar essas cinzas de Hiroshima ou de reconhecer a própria implicaçáo nessa contundente imagem do desastre.

\section{Corte: Oikonomia}

Pode-se conceber de maneira abstrata as particularidades predicativas que identificam, numa dada sociedade, as posiçôes "homem" e "mulher". E pode-se colocar como princípio geral que os direitos, estatutos, localizaçōes e hierarquias dessas posiçōes devem ser regulados pela lei num sentido igualitário. Tudo isto é excelente, mas não enraiza nenhuma espécie de universalidade na distribuição predicativa dos papéis. Para que seja o

caso, é preciso que surja a singularidade de um encontro, ou de uma declaração, onde se entrelaça um sujeito cujo avatar é justamente que ele experimente subtrativamente a diferença dos sexos. Com efeito, tal sujeito resulta, no encontro amoroso, da sintese disjuntiva das posiçóes sexuadas.

A cena verdadeira onde alguma universalidade singular se pronuncia sobre o Dois dos sexos, e finalmente sobre a diferença como tal, é, portanto, a cena amorosa, e apenas ela. Ai se dá a experimentação subjetiva indivisa da diferença absoluta (BADIOU, 2009, p. 65).

Em 1991, o filósofo Tomás Abraham apresentou, num colóquio regional da ABRALIC, sediado na Universidade Federal de Santa Catarina, o embriáo de seu livro La guerra del amor (1992), onde discutia a hipótese do amor como problema histórico-político, inquietado, na verdade, pela origem da questáo, o que é uma forma de admitir indiretamente uma preocupação pela hierarquia. Alain Badiou (1989; 2009) tem se preocupado pela questão da universalidade do amor. A ideia implica não só o assumir como risco inútil, mas também protegê-lo ou reinventá-lo, nele misturando risco, mas também aventura, antídotos, ambos contra a segurança e o bemestar. Mas, para Abraham, o amor é o cenário político e epistêmico, em que orientalistas e europeístas disputaram longamente acerca de sua definição. Baseado, assim, na clássica obra de Denis de Rougemont, Abraham disse, no colóquio, que:

[...] el matrimonio occidental, dice Rougemont, está en crisis. Existe una fisura en el amor. Hombre y mujer ya no se encuentran y cuando lo hacen fracasan. ¿Cuál es la razón por la que la unión y promesa se haya convertido en divorcio y afronta? Una razón es la nombrada: la infiltración oriental. La otra apenas mencionada por Rougemont, es que ha cambiado la mujer. Es un cambio desconcertante, aunque no parece positivo. No deja de ser loable un incremento en las libertades, pero parece tratarse de otra cosa. ¿Qué quiere la mujer? ¿Lo mismo que el hombre? El interrogante queda 
abierto, no se sabe si resulta decisivo. Porque si la culpa la tiene el oriental, la solución es más fácil. Se [sic] hay una gran promoción de que la pasión es un mensaje de guerra y muerte, que hombre y mujer no son dos biorritmos que se devoran entre si sino compañeros de un destino común, y se consiguen algunos adeptos. Pero si uno de los contractantes se dedica a otra cosa, o si ni siquiera parece esclavo de la pasión, y frente al varón al varón transmite cierta indiferencia, ¿̇a quién echarle culpas? La Dama miraba de arriba, pero era receptiva al lamento poético. ¿Qué sucede cuando no sólo mira de arriba sino que ni siquiera escucha? (ABRAHAM, 1994, p. 69).

Rita Schmidt, convidada a arguir a apresentação de Abraham, ponderou que não necessariamente, aliás, e em momento algum da história, homens e mulheres expressaram da mesma forma o que queriam, nem falaram a mesma linguagem, muito menos viveram o amor da mesma maneira, chegando assim a perguntar-se pela autêntica alteridade, que, no texto de Abraham, teria sido sequestrada:

Onde está esse sujeito outro para marcar uma especificidade de desejo, de corpo, de fala, de escrita? Se o amor nos paradigmas cultuados pela nossa tradição é um invento europeu, conforme é afirmado no texto, tenho que acrescentar, necessariamente, do homem europeu. Essas questóes me levam a ponderar sobre a experiência histórica das mulheres no passado, levadas a se espelharem, com poucas exceçôes, na imagem filtrada pela ótica do outro, a ocuparem o lugar do significante para esse outro, a tomarem como suas as histórias concebidas e contadas pelos homens. Ingenuidade seria não reconhecer que um abismo separa os sexos, e que a história do amor no ocidente e, mais especificamente, da cultura trovadoresca, tal como é investigada e tratada, perpetrou um verdadeiro aniquilamento ideológico da mulher como sujeito amoroso, submetendo a diferença erótica de uma alteridade feminina ao olhar redutor do mesmo. Será que não cantamos os nossos amores, que não sabemos o que queremos? Por que a lírica do amor cortês é vista como a fonte do ideal de amor representado na literatura do ocidente? É assim que leio o texto de Abraham, também pelo seu nãodito, pelo seu silêncio em torno de outras histórias de amor que os valores da tradiçấo literária e o seu discurso crítico relegaram ao esquecimento ao construir seus paradigmas baseados na continuidade e semelhança (SCHMIDT, 1994, p. 69).

Rita Schmidt (1994) vê corretamente que Abraham nos oferece, com o amor cortês, um paradigma de alto paradoxo. Já dizia Otto Maria Carpeaux, referindo-se a Bocaccio, que o amor cortês de suas primeiras obras era apenas o disfarce, poderíamos dizer, o suplemento, da sensualidade grosseira dos restantes relatos. Relembremos, para melhor conceituarmos a noçáo de paradigma que, para Agamben (2008, p. 33), com efeito, o Holocausto não é uma hipótese explicativa que tentaria definir a modernidade como a 
remissáo a uma causa ou a uma origem histórica, mas um paradigma, cujo objetivo seria tornar inteligível aqueles fenômenos cuja familiaridade teria escapado ou poderia ser esquiva para o olhar histórico. É isso mesmo que Rita Schmidt vê no texto de Abraham, a presença paradigmática de inclusáo e exclusão, simultaneamente apaziguadas.

Mas, retomemos também que, influído certamente pelos estudos iconológicos de Aby Warburg, o mesmo Agamben já era consciente, logo no primeiro volume da série Homo sacer, que onde havia exemplum (ou paradigma) havia exceção. Vale a pena, antes de mais nada, evocar que o termo grego parádeigma provém do verbo deiknynai: mostrar. Já o latim exemplum surge, no entanto, do supino de um verbo latino, eximere, que significa extrair ou retirar. Resgatemos, portanto, essa passagem de Homo sacer:

A validade de uma norma jurídica não coincide com sua aplicaçấo ao caso particular, por exemplo, em um processo ou em um ato executivo; ao contrário, a norma, justamente por ser geral, deve valer independentemente do caso particular. Aqui a esfera do direito mostra a sua essencial proximidade com aquela da linguagem. Como uma palavra adquire o poder de denotar, em uma instância de discurso em ato, um segmento da realidade, somente porque ela tem sentido até mesmo no próprio não-denotar (isto é, como langue distinta de parole: é o termo na sua mera consistência lexical, independentemente de seu emprego concreto no discurso), assim a norma pode referir-se ao caso particular somente porque, na exceçáo soberana, ela vigora como pura potência, na suspensão de toda referência atual. E como a linguagem pressupóe o não-linguístico como aquilo com o qual deve poder manter-se em relação virtual (na forma de uma langue, ou, mais precisamente, de um jogo gramatical, ou seja, de um discurso cuja denotação atual é mantida indefinidamente em suspenso), para poder depois denotá-lo no discurso em ato, assim a lei pressupōe o não-jurídico (por exemplo, a mera violência enquanto estado de natureza) como aquilo com o qual se mantém em relação potencial no estado de exceção. A exceção soberana (como zona de indiferença entre natureza e direito) é a pressuposição da referência jurídica na forma de sua suspensão. Em toda norma que comanda ou veta alguma coisa (por exemplo, na forma que veta o homicídio) está inscrita, como exceção pressuposta, a figura pura e insancionável do caso jurídico que, no caso normal, efetiva a sua transgressão (no exemplo, a morte de um homem náo como violência natural, mas como violência soberana no estado de exceção) (AGAMBEN, 2002, p. 28, grifos do autor).

E, a seguir, em nota apensa, o próprio Agamben ainda esclarece:

Hegel foi o primeiro a compreender em profundidade esta estrutura pressuponente da linguagem, graças à qual ela está, ao mesmo tempo, fora e dentro de si mesma, e o imediato (o não-linguístico) se revela como 
nada além de um pressuposto da linguagem. "O elemento perfeito" - ele escreveu na Fenomenologia do espírito - "em que a interioridade é tão exterior quanta a exterioridade é interna, é a linguagem" [...]. Como somente a decisão soberana sobre o estado de exceção abre o espaço no qual podem ser traçados confins entre o interno e o externo, e determinadas normas podem ser atribuídas a determinados territórios, assim somente a língua como pura potência de significar, retirando-se de toda concreta instência de discurso, divide o linguístico do não-linguístico e permite a abertura de âmbitos de discurso significantes, nos quais a certos termos correspondem certos denotados. A linguagem é o soberano que, em permanente estado de exceçâo, declara que não existe um fora da língua, que ela está sempre além de si mesma. A estrutura particular do direito tem seu fundamento nesta estrutura pressuponente da linguagem humana. Ela exprime o vínculo de exclusão inclusiva ao qual está sujeita uma coisa pelo fato de encontrar-se na linguagem, de ser nominada. Dizer, neste sentido, é sempre ius dicere (AGAMBEN, 2002, p. 29, grifos do autor).

Portanto, no raciocínio de Agamben, mas também na ponderação restritiva de Rita Schmidt ao julgamento universal de Tomás Abraham, ou mesmo na leitura política de González, comprova-se que a sociedade contemporânea (sociedade de imagens de puro espetáculo) é, sob esse ponto de vista, uma sociedade em que o poder, em seu aspecto "glorioso", torna-se inseparável da oikonomia e do governo. Ao identificarem, integralmente, glória e oikonomia na forma aclamativa do consenso, a característica específica das democracias contemporâneas é justamente a de produzir imagens apolis, porque não nos esqueçamos de que o conceito de oikonomia, entre os gregos, refere-se, exclusivamente, a um paradigma gestionário, mas não necessariamente epistêmico. Tal como o neoliberalismo hoje dominante, trata-se de uma prática política exclusivamente orientada a um fim pragmático, com total prescindência de reverberaçôes éticas ou históricas.

\section{Coda}

Jacques Rancière diferenciava, num ensaio já antigo, três aspectos relevantes na intervenção de um intelectual. Ora ele é, como adjetivo, algo que se predica de atos e náo de indivíduos e, nesse sentido, na medida em que agir com o pensamento é característico de todos, e não apenas de alguns, para tornar-se um substantivo, foi preciso que o termo se aplicasse a uma classe específica de indivíduos, cuja singularidade consistiria em somente realizar atos de pensamento. Mas assim como náo existe o indivíduo chamado 
intelectual, também não há motivos para identificar esses atos com açôes promovidas pelos assim chamados "homens de letras", os eruditos. Nesse sentido, argumenta Rancière, ninguém tem direito a falar como intelectual, porque todo mundo já é um intelectual. Mas, para não diluirmos o conceito numa passividade niilista, Rancière definia o intelectual como um índice que remete às operaçôes de divisão, através das quais uma sociedade se torna visível para si própria como uma partilha entre nomes, tarefas e modos de ser (1997). Uma partilha de sensibilidades (2005) 5 .

Trocando em miúdos, quando González analisa a imagem do mestre e nấo vê, como pretendia, o poderoso, apenas um mestre indigente, mas um mestre emancipatório, ou quando Schmidt cinde o conceito (amor, laço social), que o intelectual enuncia universalmente, para apontar sua falha, sua falta, estamos diante de autênticas operaçóes de emancipação. Em texto mais antigo ainda, originalmente de 1987, o mesmo Rancière já admitia que náo é da ciência do mestre que os alunos aprendem. A título conclusivo, relembremos esta passagem, que algo nos diz também do trabalho pedagógico de Rita Schmidt:

Ele havia sido mestre por força da ordem que mergulhara os alunos no círculo de onde eles podiam sair sozinhos, quando retirava sua inteligência para deixar as deles entregues àquela do livro. Assim se haviam dissociado as duas funçôes que a prática do mestre explicador vai religar, a do sábio e a do mestre. Assim se haviam igualmente separado, liberadas uma da outra, as duas faculdades que estấo em jogo no ato de aprender: a inteligência e a vontade. Entre o mestre e o aluno se estabelecera uma relação de vontade a vontade: relação de dominação do mestre, que tivera por consequência uma relação inteiramente livre da inteligência do aluno com aquela do livro - inteligência do livro que era, também, a coisa comum, o laço intelectual igualitário entre o mestre e o aluno. Esse dispositivo permitia destrinchar as categorias misturadas do ato pedagógico e definir exatamente o embrutecimento explicador. Há embrutecimento quando uma inteligência é subordinada

\footnotetext{
${ }^{5}$ A rigor, Adorno e Horkheimer (1985, p. 227-228) já abordaram essa questão em um dos fragmentos esparsos de Dialética do esclarecimento, ao argumentarem que a filosofia acredita na divisão do trabalho e que ela exista para os homens, assim como acredita no progresso e que ele conduza à liberdade. É por isso que facilmente ela entra em conflito com a divisão do trabalho e com o progresso, porque o pensamento dá expressão à contradição entre a crença e a realidade e, assim fazendo, restringe-se estritamente ao fenômeno historicamente determinado. Para ela, diferentemente dos jornais, os crimes em massa, apesar de suas proporçóes, não são mais interessantes do que a eliminação de alguns internados em asilos. Ela não dá à intriga do estadista comprometido com o fascismo nenhuma prioridade sobre um simples linchamento, nem privilegia a vertiginosa publicidade da mídia em detrimento a um simples anúncio funerário. Por isso, em relação ao existente, ela se mantém, ao mesmo tempo, alheia e compreensiva. Sua voz pertence ao objeto, mas sem que este a busque: ela é a voz da contradição que, sem ela, não se faria ouvir, mas mesmo assim, triunfaria em silêncio.
} 
a outra inteligência. $O$ homem - e a criança, em particular - pode ter necessidade de um mestre, quando sua vontade náo é suficientemente forte para colocá-la e mantê-la em seu caminho. Mas a sujeição é puramente de vontade a vontade. Ela se torna embrutecedora quando liga uma inteligência a uma outra inteligência. No ato de ensinar e de aprender, há duas vontades e duas inteligências. Chamar-se-á embrutecimento à sua coincidência. $\mathrm{Na}$ situaçáo experimental criada por Jacotot, o aluno estava ligado a uma vontade, a de Jacotot, e a uma inteligência, a do livro, inteiramente distintas. Chamar-se-á emancipação à diferença conhecida e mantida entre as duas relaçốes, o ato de uma inteligência que não obedece senáo a ela mesma, ainda que a vontade obedeça a uma outra vontade (RANCIÈRE, 2002, p. 31-32).

\section{Referências}

ABRAHAM, Tomás. La guerra del amor. In: ANTELO, Raúl (Org.). Identidade e representaçáo. Florianópolis, ABRALIC/Curso de PósGraduação em Letras da UFSC, 1994. p. 65-70.

ADORNO, Th.; HORKHEIMER, Max. Filosofia e divisão do trabalho. In: Dialética do Esclarecimento. 2. ed. Trad. Guido A. de Almeida. Rio de Janeiro, Jorge Zahar, 1985, p. 227-228.

AGAMBEN, Giorgio. Face au cinéma et à l'Histoire: à propos de Jean-Luc Godard, Le Monde (Supplément Livres), Paris, 6 out., I, p. X-XI, 1995.

Quel che resta di Auschwitz. L'archivio e il testimone, Torino, Bollati Boringhieri, 1998.

. Signatura rerum. Sul metodo, Torino, Bollati Boringhieri, 2008.

. Homo sacer: o poder soberano e a vida nua I. Trad. H. Burigo. Belo Horizonte, UFMG, 2002.

BADIOU, Alain. Manifeste pour la philosophie. Paris, Seuil, 1989.

Oito teses sobre o universal. 2008. Disponível em: <https:// estudosbadiouianos. files.wordpress.com/2012/12/badiou-oito-teses-sobreo-universal.pdf>. Acesso em: 21 ago. 2017.

. Eloge de l'amour. Paris, Flammarion, 2009. 
BENJAMIN, Walter. A obra de arte na época de sua reprodutibilidade técnica. In: Obras escolhidas. v. 1. Magia e técnica, arte e política. Ensaios sobre literatura e história da cultura. Trad. Sérgio Paulo Rouanet. Pref. Jeanne Marie Gagnebin. São Paulo, Brasiliense, 1987. p. 165-196.

Che cos'è il aura? In: Charles Baudelaire. Un poeta lirico nell' età del capitalismo avanzato. Ed. Giorgio Agamben, Barbara Chitussi e Clemens-Carl Härle. Vicenza, Neri Pozza, 2013. p. 169-170.

BUCK-MORSS, Susan. Estética e anestética: o "ensaio sobre a obra de arte" de Walter Benjamin reconsiderado. Travessia, n. 33, Florianópolis, p. 1141, ago./dez. 1996.

CASTRO, Edgardo. Cuestiones de método: la problemática del ejemplo en Foucault y Agamben. Res Publica: Revista de Filosofía Política, n. 28, Buenos Aires, 2012. p. 53-75.

DÉOTTE, Jean-Louis. Le musée, l’origine de l'esthétique. Paris, L'Harmattan, 1993.

L’Homme de verre: esthétiques benjaminiennes. Paris/Montréal, L'Harmattan, 1997.

L'époque des appareils. Paris, Lignes, 2004.

Appareils et formes de la sensibilité. Paris, L'Harmattan, 2005.

Qu'est-ce qu'un appareil? Paris, L'Harmattan, 2006.

. Walter Benjamin et la forme plastique. Paris, L'Harmattan, 2012.

Walter Benjamin: la perspective comme fantasmagorie. Appareil,

n. 15, p. 1-9, 2015. Disponível em: <http://appareil.revues.org/1971>. Acesso em: 21 ago. 2017.

Video y desaparición. El resplandor. Revista de la Escuela de cine, Universidad de Valparaíso, p. 11-23, 2015.

DIDI-HUBERMAN, Georges. Imagens apesar de tudo. Trad. V. Brito e J. P. Cachopo. Lisboa, KKYM, 2012.

Quand les images prennent position (L'CEil de l'histoire, 1), Paris, Minuit, 2009.

Minuit, 2012.

Peuples exposés, peuples figurants (L'CEil de l'Histoire, 4). Paris, 
. A imagem sobrevivente: história da arte e tempo dos fantasmas segundo Aby Warburg. Trad. Vera Ribeiro. Rio de Janeiro, Contraponto, 2013.

. Passés cités par JLG (L'Cil de l'Histoire, 5). Paris, Minuit, 2015.

. Peuples en larmes, peuples en armes (L'CEil de l'histoire, 6). Paris, Minuit, 2016.

. Soulèvements. Paris, Gallimard/Jeu de paume, 2016.

. "Puissance de ne pas", ou la politique du désoeuvrement. Critique Paris, p. 836-837, jan. 2017.

DICKINSON, Colby. Agamben and Theology. Londres: T\&T Clark International, 2011.

ESPOSITO, Roberto. Immunitas. Protezione e negazione della vita. Torino, Einaudi, 2002.

70, 2010.

Bios. Biopolítica e Filosofia. Trad. M. Freitas da Costa. Lisboa: Ed.

FELSTINER, John. Translating as transference. In: MUELLERVOLLMER, K. e IRMSCHER, M. Translating Literature. Translating culture. New vistas and aproaches in Literary Studies. California: Stanford University Press, 1998. p. 327-336.

2001.

. Paul Celan: Poet, Survivor, Jew. London: Yale University Press,

FOUCAULT, Michel. Naissance de la biopolitique. Paris: GallimardSeuil, 2004a.

Sécurité, territoire, population. Paris: Gallimard-Seuil, $2004 \mathrm{~b}$.

FRIEDLANDER, Saul. (Ed.). Probing the Limits of Representation. Nazism and the Final Solution. Cambridge University Press, Cambridge (Mass.), 1992.

GINZBURG, Carlo. Storia notturna. Torino: Giulio Einaudi Editore, 1989.

. Il formaggio e i vermi: Il cosmo di un mugnaio del'500. Torino: Giulio Einaudi Editore, 1976. 
GONZALEZ, Horacio. Escritos en carbonilla: figuraciones, destintos, retratos. Buenos Aires: Colihue, 2006.

JAY, Martin. Downcast Eyes: the denigration of vision in twentieth-century french thought. Los Angeles: University of California Press, 1993.

LA CAPRA, Dominick. Rethinking Intellectual History. Text, Context and Language. Cornell University Press, Ithaca, New York 1983.

LANG, Berei. Act and Idea in the Nazi Genocide. Chicago University Press, Chicago, 1990.

MONTANI, Pietro. Esthétique et an-esthétique du biopouvoir. Klesis. La biopolitique. Paris, n. 8, p. 62-71, 2008.

RANCIĖRE, Jacques. A vertigem cinematográfica: Hitchcock-Vertov e retorno. In: As distâncias do cinema. Trad. Estela dos Santos Abreu. Rio de Janeiro, Contraponto, 2012, p. 29-51.

. Ce qu' intellectuel peut vouloir dire. Lignes, n. 32, p. 116-120, 1997.

A partilha do sensível. Trad. Mônica Costa Netto. São Paulo, EXO Experimental; Ed. 34, 2005.

. O mestre ignorante. Cinco lições sobre a emancipação intelectual. Trad. Lílian do Valle, Belo Horizonte, Autêntica, 2002.

ROUGEMONT, Denis de. O amor e o Ocidente. Trad. Paulo Brandi e Ethel Brandi. Rio de Janeiro, Guanabara, 1988.

SCHMIDT, Rita Terezinha. O cerco à história: sedução ou provocação?. In: ANTELO, Raúl (Org.). Identidade e representaçáo. Florianópolis, ABRALIC/Curso de Pós-Graduação em Letras da UFSC, 1994. p. 71-79.

WHITE, Hayden. Meta-história. A imaginação histórica do século XIX. Trad. José L. de Melo. São Paulo: Edusp, 1995. 